\title{
SISTEM INFORMASI GEOGRAFIS WISATA GUNUNG DI PEKALONGAN BERBASIS ANDROID
}

\author{
Aslam Fatkhudin, Saifudin'1 \\ Program Studi Manajemen Informatika \\ Politeknik Muhammadiyah Pekalongan, Jawa Tengah \\ Fatkhudin@gmail.com
}

\begin{abstract}
ABSTRAK
Selain terkenal dengan Batiknya, Pekalongan juga terkenal dengan destinasi wisata, keindahan seni dan budayanya. Keindahan alam yang ada di kota yang terletak di kawasan jalur pantai utara Jawa ini, juga memiliki segudang destinasi wisata alam yang ditawarkan, seperti curug, pantai dan pegunungan. Pariwisata lokal dapat membuat perekonomian warga meningkat dan juga bisa menjadi media promosi untuk kekayaan lokal. Tetapi dengan banyaknya destinsai wisata yang ada, masih banyak yang belum terekspose dan minim informasi seperti obyek wisata mengenai pegunungan di Pekalongan. Padahal di era digital ini, seharusnya informasi bisa terbuka lebar kemedia massa baik itu media cetak maupun media elektronik. Apalagi dengan perkembangan teknologi saat ini terutama pada ponsel yang sekarang sudah menjadi ponsel pintar, membuat masyarakat menjadi tergantung pada teknologi tersebut karena mudah penggunaannya. Fenomena ponsel pintar ini yang mengusung sistem operasi Android yang bersifat open source, memungkinkan masyarakat untuk ikut mengembangkan sistem operasi tersebut maupun membuat aplikasi yang ada di dalamnya. Berdasarkan permasalahan itu, maka dibuatlah aplikasi Sistem Informasi Geografis (SIG) Wisata Gunung Di Pekalongan berbasis Android. Hasil dari penelitian ini adalah aplikasi ini dapat memberikan informasi kepada masyarakat tentang wisata gunung, manfaat pendakian, prediksi cuaca, keselamatan dan keamanan, mudah, cepat dan efektif sehingga dapat membantu wisatawan untuk mengenal wisata gunung di Pekalongan.
\end{abstract}

Kata Kunci : Sistem Informasi Geografis, Wisata Gunung, Android System.

\begin{abstract}
Besides being famous for its Batik, Pekalongan is also famous for its tourist destinations, the beauty of art and culture. The natural beauty in the city, which is located in the northern coast of Java, also has a myriad of natural tourist destinations on offer, such as waterfalls, beaches and mountains. Local tourism can make the people's economy increase and can also be a media campaign for local wealth. But with the many tourist destinations that exist, there are still many who have not been exposed and lack information such as tourism objects in the mountains in Pekalongan. Even though in this digital era, information should be widely available both in print and electronic media. Especially with the development of current technology, especially on mobile phones that are now becoming smart phones, making people become dependent on these technologies because of their easy use. The phenomenon of this smart phone that carries the Android operating system that is open source, allows people to participate in developing the operating system and create applications that are in it. Based on these problems, the application of Geographic Information System (GIS) for Mountain Tourism in Pekalongan is based on Android. The results of this study are that this application can provide information to the public about mountain tourism, the benefits of climbing, weather prediction, safety and security, easy, fast and effective so that it can help tourists to get to know mountain tourism in Pekalongan.
\end{abstract}

Keywords: Geographic Information System, GIS, tourism, mountain, android. 


\section{PENDAHULUAN}

Selain terkenal dengan batiknya, Pekalongan terkenal dengan destinasi wisatanya, keindahan seni dan budaya. Keindahan alam yang ada di kota yang terletak di kawasan jalur pantai utara jawa ini, juga memiliki segudang destinasi wisata alam yang ditawarkan, seperti curug, pantai dan pegunungan. Padahal pariwisata lokal dapat membuat perekonomian warga meningkat dan juga bisa menjadi media promosi untuk kekayaan lokal. Tetapi dengan banyaknya destinsai wisata diatas masih banyak yang belum terekspose kemedia seperti gunung-gunung di Pekalongan dan informasinya masih minim padahal di era digital ini seharusnya informasi bisa terbuka lebar kemedia masa baik itu media cetak, media elektronik dan media siber [1].

Perkembangan teknologi terutama pada ponsel, yang sekarang sudah menjadi ponsel pintar (smartphone) yang menggunakan teknologi sistem operasi Android yang bersifat open source, memungkinkan penggunaan smartphone untuk membuat aplikasi berbasis sistem operasi Android yang dapat dijalankan pada smartphone. Dengan adanya teknologi Android, pengguna smartphone dapat melakukan kreasi sendiri ataupun mengunduh aplikasi Android untuk kemudian digunakan pada telepon selularnya. Penggunaan Android yang semakin luas menjadikan aplikasi android sebagai suatu aplikasi yang mudah diakses oleh semua orang. Pengguna smartphone Indonesia juga bertumbuh dengan pesat. Lembaga riset digital marketing Emarketer memperkirakan pada 2018 jumlah pengguna aktif smartphone di Indonesia lebih dari 100 juta orang. Dengan jumlah sebesar itu, Indonesia akan menjadi negara dengan pengguna aktif smartphone terbesar keempat di dunia setelah Cina, India, dan Amerika [2].

Berdasarkan permasalahan diatas, maka penulis tertarik untuk membuat Sistem Informasi Geografis Wisata Gunung di Pekalongan Berbasis Android yang hanya berfokus pada macam-macam gunung di Pekalongan. Manfaat yang dapat dihasilkan dari penelitian ini diantaranya dapat membantu masyarakat/wisatawan dalam meng-explore informasi seputar wisata gunung di Pekalongan. Aplikasi ini nantinya juga bisa digunakan oleh dinas terkait misalnya Dinas Pariwisata Pekalongan dalam mempromosikan dan mengelola informasi wisata pegunungan di daerahnya.

\section{TINJAUAN PUSTAKA}

Beberapa penelitian mengenai Sistem Informasi Geografis berbasis Android memang sudah pernah dilakukan sebelumnya. Diantaranya penelitian dengan judul Sistem Informasi Geografis Objek Wisata Wilayah Puncak Kabupaten Bogor Berbasis Android. Penelitian ini dilatar belakangi oleh sektor pariwisata memberikan kontribusi yang besar untuk kabupaten Bogor khususnya wilayah puncak, akan tetapi informasi tempat wisata puncak sangat minim dan belum menyesuaikan dengan perkembangan teknologi. Maka dari itu penulis membangun aplikasi peta petunjuk objek pariwisata untuk wilayah Puncak kabupaten Bogor yang berguna dalam memperoleh informasi daerah-daerah wisata dan penunjuk untuk para wisatawan yang menggunakan ponsel sistem operasi android 2.3.3 dan dapat diakses secara online [3].

Penelitian lainnya dengan judul Sistem Informasi Geografis Track Gunung Awu Berbasis Web. Penelitian ini dilatar belakangi minimnya informasi tentang destinasi wisata alam di Kabupaten Kepulauan Sangihe dan belum dikelola secara maksimal, salah satunya wisata alam Gunung Awu. Padahal di Kabupaten Kepulauan Sangihe, Sulawesi Utara merupakan salah satu daerah yang memiliki berbagai jenis potensi wisata seperti wisata alam, wisata budaya maupun wisata sejarah. Maka dari itu penulis membangun sebuah Sistem Informasi Geografis Track Gunung Awu Berbasis Web. Dengan adanya sistem ini, diharapkan dapat membantu untuk memberikan informasi yang cepat dan akurat, serta memudahkan dalam penentuan jalur yang akan dilalui dari titik start hingga sampai ke puncak Gunung Awu [4].

Persamaan penelitian-penelitian yang diuraikan diatas dengan penelitian ini yaitu untuk memberikan kemudahan bagi wisatawan dalam mendapatkan informasi mengenai lokasi wisata. Adapun perbedaannya adalah aplikasi ini berbasis Android dengan sistem operasi terbaru, sehingga diharapkan memiliki beberapa kelebihan baik dari segi kemudahan operasional maupun kecepatan akses. Selain itu, aplikasi ini juga dilengkapi script yang dapat membaca GPS sehingga bisa mengetahui jarak pengguna dan tempat wisata. Aplikasi ini juga sudah terintegrasi dengan aplikasi Google Maps sehingga bisa memberikan gambaran jalur/rute langsung ke lokasi tujuan.

\section{METODE YANG DIUSULKAN}

Metode yang digunakan penulis adalah metode pengembangan sistem Waterfall, yang terdiri dari 1) analisis 2) design 3) coding 4) perancangan dan design sistem serta 5) maintenance. Dari kelima tahapan tersebut, penulis hanya sampai pada tahapan ke-4. Pembahasan mengenai tiap tahapan akan penulis jelaskan sebagai berikut. Tahap analisis sudah penulis uraikan pada bagian pendahuluan.

\subsection{Design Sistem}

Design sistem yang digunakan adalah Diagram Konteks (Context Diagram), Data Flow Diagram (DFD) dan Entity Relationship Diagram (ERD)

\section{a. Context Diagram}

Pada Diagram Context digambarkan suatu proses dan ruang lingkup sistem seperti yang ditunjukkan pada gambar 3.1. berikut ini : 


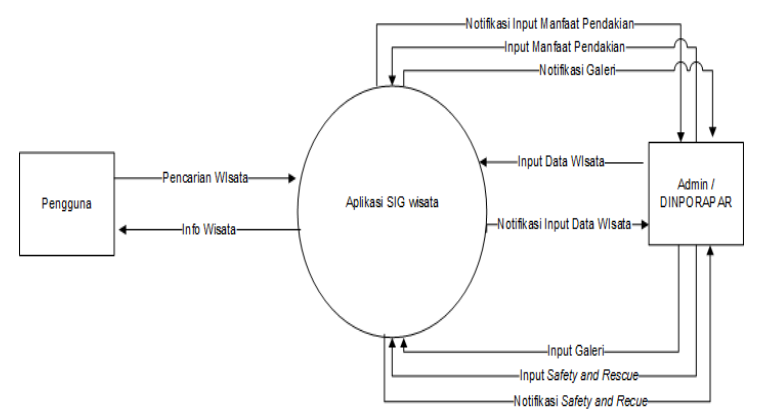

Gambar 3.1. Context Diagram

Dari sistem yang diusulkan terdapat dua entitas yang saling berkaitan, yaitu entitas pengguna dan admin. Admin akan menginput data wisata ke sistem yang kemudian diproses menjadi informasi seperti informasi wisata.

\section{b. DFD}

DFD merupakan turunan dari Context Diagram yang menggambarkan rancangan alur data yang bergerak pada sebuah sistem. Ada beberapa level dalam rancangan DFD, dianataranya DFD Level 0 yang ditampilkan pada gambar 3.2. berikut ini :

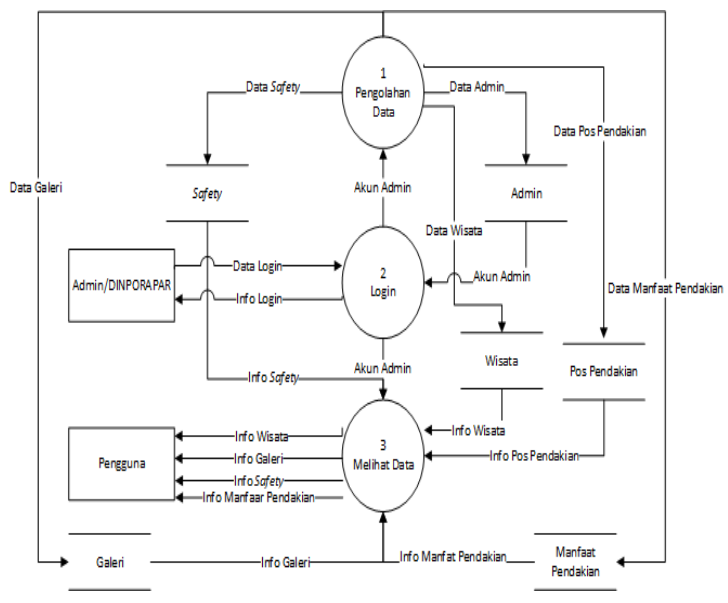

Gambar 3.2. DFD Level 0

DFD Level 0 pada gambar 3.2. diatas terdapat 3 proses yaitu pengolahan data, login dan melihat data; 6 data store yaitu safety, admin, wisata, pos pendakian, galeri dan manfaat pendakian; serta 2 entitas yaitu Admin dan Pengguna. Hanya satu entitas yang harus melewati proses Login terlebih dahulu agar bisa melakukan proses yang lainnya.

\section{c. ERD}

ERD menggambarkan hubungan antara data dalam basis data. Adapun ERD aplikasi dari penelitian ini adalah seperti yang tampak pada gambar 3.3. berikut ini

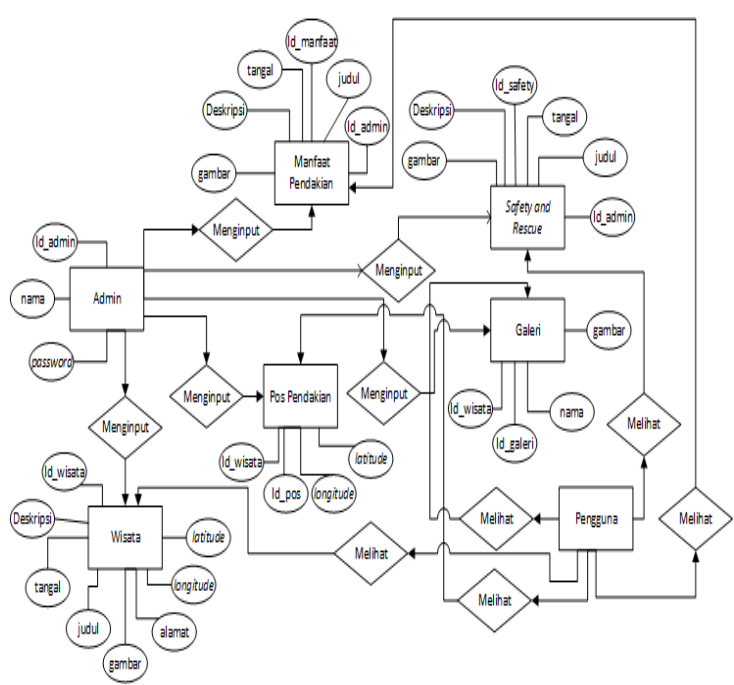

Gambar 3.3. ERD

Dari rancangan pada gambar 3.3 diatas terdapat 7 entitas, dimana masing-masing entitas memiliki beberapa atribut. Entitas admin mempunyai 3 atribut, Pos Pendakian dengan 5 atribut, manfaat pendakian memiliki 6 atribut, wisata mempunyai 7 atribut, safety and rescue mempunyai 6 atribut, dan galeri memiliki 4 atribut.

\subsection{Perancangan dan Design Sistem}

a. Rancangan Halaman Menu User

Halaman ini merupakan tampilan menu utama untuk user yang terdiri dari Wisata Gunung, Manfaat Pendakian dan Safety and Rescue yang digunakan user untuk mencari informasi yang diinginkan. Rancangan halaman ini seperti ditunjukkan pada gambar 3.4. berikut :

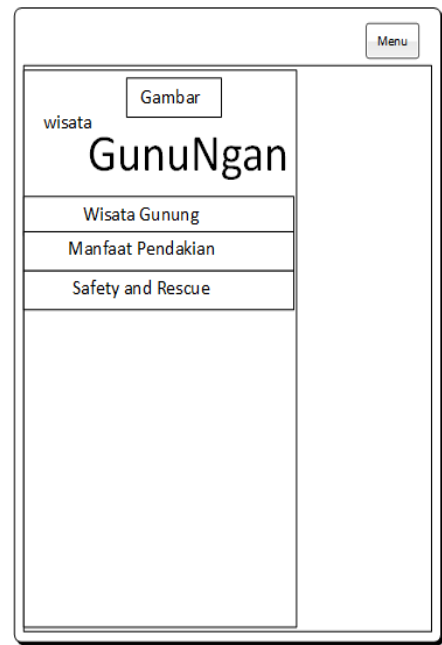

Gambar 3.4. Rancangan Halaman Menu User

b. Rancangan Halaman Wisata Gunung

Halaman ini menampilkan data wisata, lokasi wisata dan fotonya. Rancangan halaman ini seperti ditunjukkan pada gambar 3.5. berikut : 


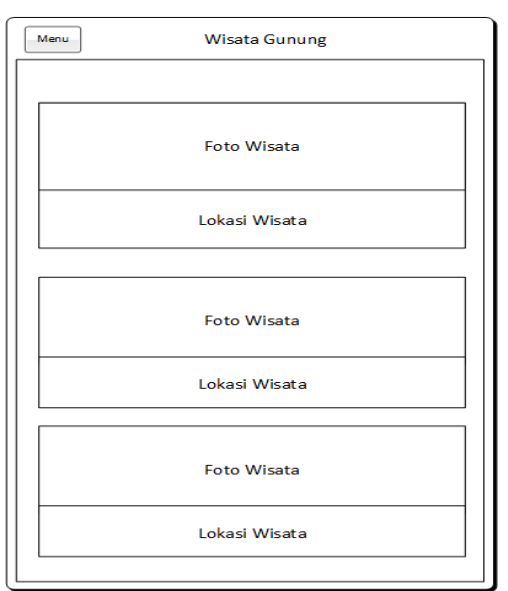

Gambar 3.5. Rancangan Halaman Wisata Gunung

c. Rancangan Halaman Login Admin

Halaman ini muncul pertama kali saat admin membuka aplikasi. Berisi inputan username dan password untuk masuk ke aplikasi back-office-nya. Rancangan halaman ini seperti ditunjukkan pada gambar 3.6. berikut :

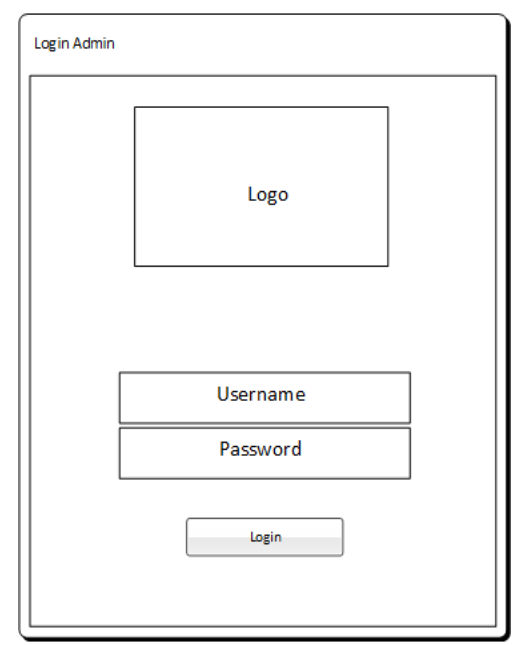

Gambar 3.6. Rancangan Halaman Menu Admin

d. Rancangan Halaman Menu Admin

Halaman ini menampilkan menu utama dari aplikasi untuk admin yang berfungsi untuk mengelola informasi Wisata Gunung, Manfaat Pendakian, Pos Pendakian, Galeri, Safety and Rescue. Rancangan halaman ini seperti ditunjukkan pada gambar 3.7. berikut :

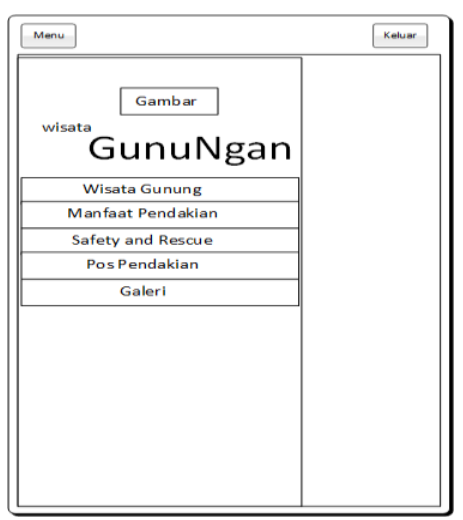

Gambar 3.7. Rancangan Halaman Menu Admin

e. Rancangan Halaman Tambah Data Wisata

Halaman ini berfungsi untuk menambah data wisata. Rancangan halaman ini seperti ditunjukkan pada gambar 3.8. berikut :

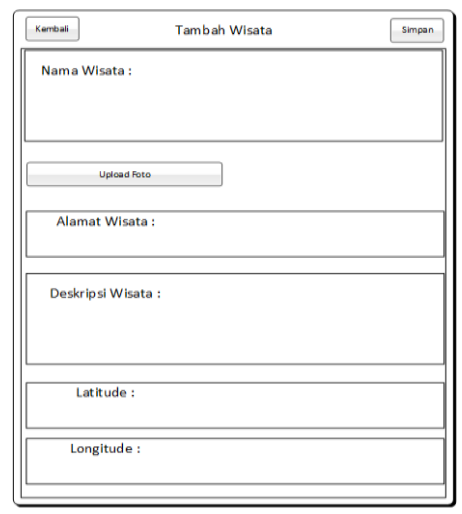

Gambar 3.8. Rancangan Halaman Tambah Data Wisata

f. Rancangan Halaman Tambah Artikel

Halaman ini berfungsi untuk menambah data Artikel misalnya artikel mengenai manfaat Pendakian, Safety and Resue. Rancangan halaman ini seperti ditunjukkan pada gambar 3.9. berikut :

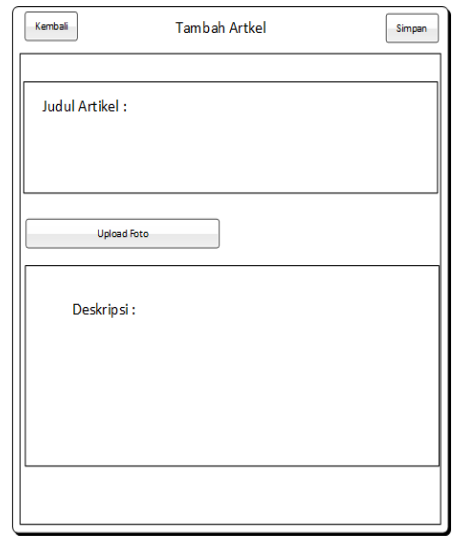

Gambar 3.9. Rancangan Halaman Tambah Artikel 


\section{HASIL PENELITIAN}

Penelitian ini menghasilkan suatu aplikasi Sistem Informasi Geografis berbasis Android. Tampilan yang ada merupakan implementasi dari perancangan desain system. Tampilan-tampilan tersebut sebagai berikut :

\subsection{Halaman Menu User}

Merupakan tampilan menu utama untuk user yang terdiri dari Wisata Gunung, Manfaat Pendakian dan Safety and Rescue yang digunakan user untuk mencari informasi yang diinginkan. Halaman ini seperti ditunjukkan pada gambar 4.1. berikut :

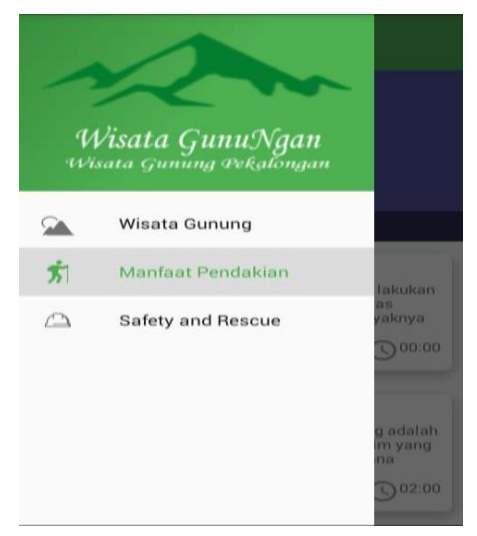

Gambar 4.1. Halaman Menu User

\subsection{Halaman Wisata Gunung}

Halaman ini menampilkan data wisata, lokasi wisata dan fotonya. Halaman ini seperti ditunjukkan pada gambar 4.2. berikut :

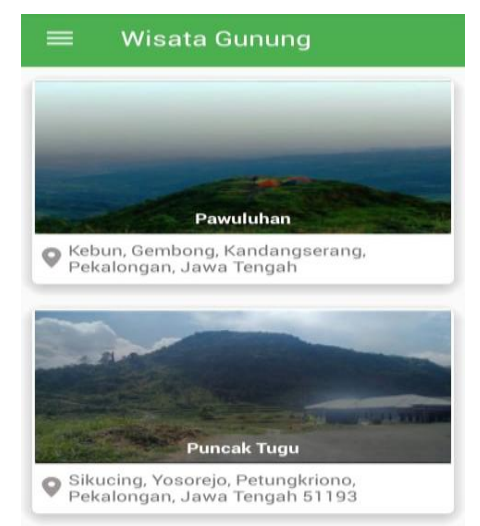

Gambar 4.2. Halaman Wisata Gunung

\subsection{Halaman Login Admin}

Halaman ini muncul pertama kali saat admin membuka aplikasi. Berisi inputan username dan password untuk masuk ke aplikasi back-office-nya. Halaman ini seperti ditunjukkan pada gambar 4.3. berikut :
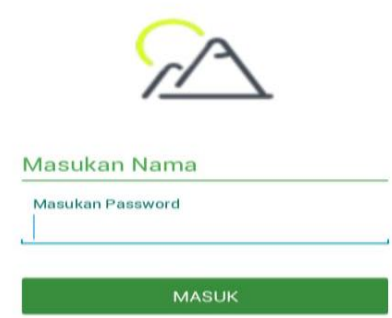

Gambar 4.3. Halaman Login Admin

\subsection{Halaman Menu Admin}

Halaman ini menampilkan menu utama dari aplikasi untuk admin yang berfungsi untuk mengelola informasi Wisata Gunung, Manfaat Pendakian, Pos Pendakian, Galeri, Safety and Rescue. Halaman ini seperti ditunjukkan pada gambar 4.4. berikut :

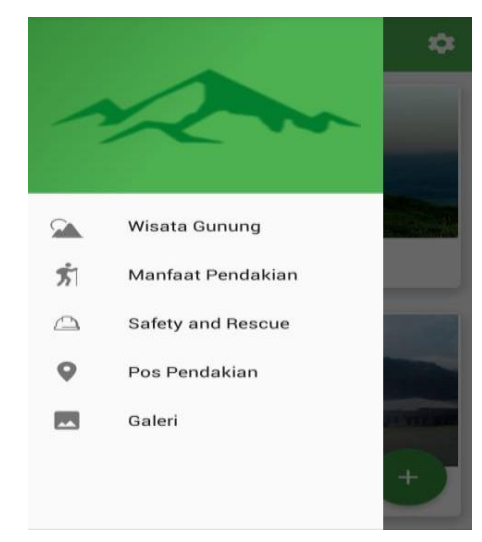

Gambar 4.4. Halaman Menu Admin

\subsection{Halaman Tambah Data Wisata}

Halaman ini berfungsi untuk menambah data wisata. Halaman ini seperti ditunjukkan pada gambar 4.5. berikut :

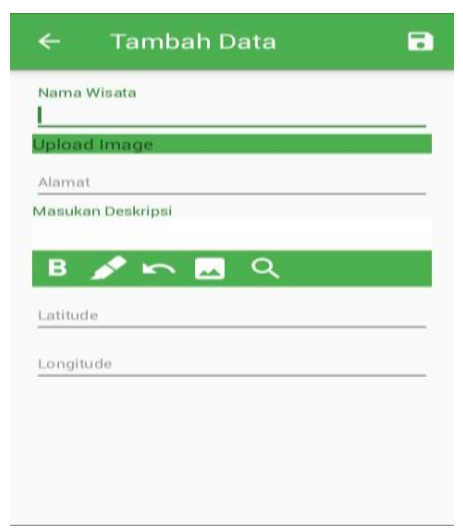

Gambar 4.5. Halaman Tambah Data Wisata 


\subsection{Halaman Tambah Artikel}

Halaman ini berfungsi untuk menambah data Artikel misalnya artikel mengenai manfaat Pendakian, Safety and Resue.. Halaman ini seperti ditunjukkan pada gambar 4.6. berikut :

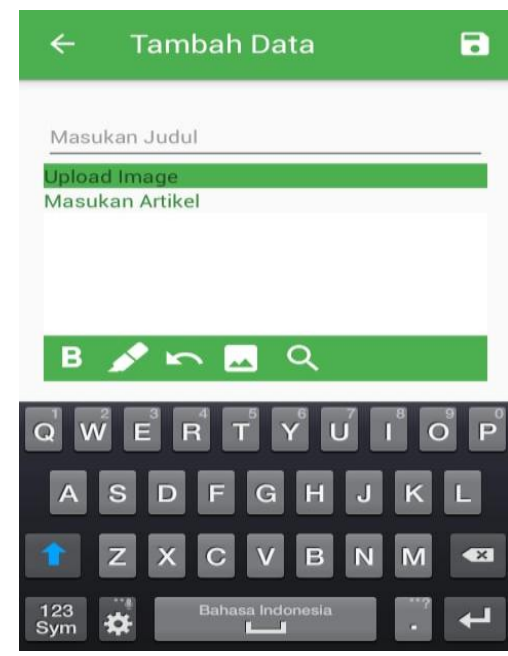

Gambar 4.6. Halaman Tambah Artikel

\section{KESIMPULAN}

Sistem Informasi Geografis Wisata Gunung di Pekalongan berbasis Android pada penelitian ini dibuat dengan menggunakan Android Studio sebagai front-end, PHP sebagai back-end, dan MySQL sebagai database-nya. Aplikasi ini berisi menu yang menginformasikan data wisata gunung dan informasi terkait, yaitu menu wisata gunung, manfaat pendakian, safety and rescue sebagai front end. Aplikasi ini dibuat manyelesaikan permasalahan yang ada, antara lain memberikan informasi pada wisatawan tentang wisata gunung, prediksi cuaca, artikel terkait manfaat pendakian, safety and rescue.

\section{Daftar Pustaka}

[1] T. Apriadi, "Developer Android Studio," Android Studio, 2012. [Online]. Available: https://www.developer.android.com/studio/in tro. [Diakses 1 Agustus 2018].

[2] I. Rahmayani, "Kominfo," Kementerian Komunikasi dan Informatika RI, 1 Agustus 2017. [Online]. Available: https://kominfo.go.id/content/detail/6095/ind onesia-raksasa-teknologi-digitalasia/0/sorotan_media. [Accessed 2 Januari 2019].

[3] A. E. Saputra, "Sistem Informasi Geografis Objek Wisata Wilayah Puncak Kabupaten
Bogor Berbasis Android," Jurnal Ilmiah Informatika Komputer - Universitas Gunadarma, vol. III, no. 12, pp. 12-24, 2012.

[4] F. Mua, "Sistem Informasi Geografis Track Gunung Awu Berbasis Web," Jurnal Ilmiah Behongang, vol. III, no. 12, pp. 5-12, 2017. 